\title{
Campamentos romanos en España a través de los textos clásicos *
}

\author{
Ángel Morillo Cerdán **
}

El análisis de los textos clásicos es una fuente de extraordinaria importancia para el conocimiento de la localización y las características constructivas de los campamentos romanos. Sin embargo, las referencias específicas dedicadas por los historiadores y geógrafos grecolatinos a esta cuestión no son muy numerosas. La mayor parte se concentran en textos que describen de forma minuciosa las técnicas de castramentación. Los más completos son, por un lado, un largo pasaje de las Historias de Polibio (VI, 28, 10 a VI, 42, 6), de la segunda mitad del siglo II a.C. y, por otro, la obra de Higinio, De Metatione Castrorum, también conocida como De Munitionibus Castrorum, redactada en las primeras décadas del siglo II d.C., aunque encontramos noticias dispersas en un buen número de autores entre los que se encuentran Tito Livio (Ab Urbe Condita), Vitrubio (De Architectura) o Vegecio (Epitome rei militari), por poner tan sólo algunos ejemplos.

Junto a estos textos de edilicia campamental, en la mayoría de las ocasiones las referencias a campamentos adoptan la forma de citas puntuales en los monótonos y reiterativos relatos sobre campañas militares llevadas a cabo por generales romanos por todo el ámbito del imperio. Los historiadores antiguos no suelen prestar demasiada atención a la localización concreta de los recintos castrenses, limitándose a indicar, en los casos de mayor precisión, su distancia respecto al núcleo habitado más próximo. Podemos atribuir este desinterés al hecho de que el establecimiento de un campamento era una costumbre habitual por el ejército romano, sobre lo que no era preciso informar al lector, ya que siempre

\footnotetext{
* Este artículo constituye la parte inicial del que con título “Fortificaciones campamentales de época romana en España", recientemente publicado en el Archivo Español de Arqueología $64,1991,135-190$.

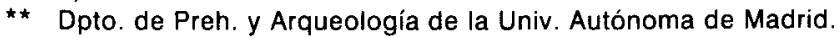


se sobreentendía. Tan sólo en los casos en que era preciso hacer hincapié en algún aspecto táctico o estratégico se proporcionaban datos complementarios sobre la posición del campamento. En este sentido resulta paradigmática la minuciosa descripción del cerco establecido por $\mathrm{P}$. Cornelio Escipión el Africano en torno a Numancia.

César, constituye en éste, como en tantos otros campos, una excepción. El dictador nos informa en sus escritos De Bello Gallico y De Bello Civile sobre aspectos poco conocidos de las técnicas de fortificación y aprovechamiento de la topografía del terreno en beneficio propio. Algunas de ellas debían ser utilizadas de forma habitual por el ejército romano, mientras otras parecen invenciones originales del genial estadista.

Debemos suponer, por lo tanto, que, junto a los campamentos mencionados en las fuentes, existió un elevado número no recogidos en los textos clásicos, cuya identificación es, a todas luces, completamente inviable, a no ser que medie el hallazgo fortuito.

No es éste el lugar adecuado para exponer los datos conocidos sobre la morfología y la estructura interna del campamento, temas por otra parte suficientemente aclaradas en trabajos muy recientes (LENOIR 1986, 329336). Especial trascendencia reviste, sin embargo, la cuestión de los materiales constructivos. Las fuentes nunca informan a este respecto. La mayoría de los autores ha dado por supuesto que los campamentos temporales eran de madera y los estables - generalmente los cuarteles de invierno o hiberna -, estaban construidos en piedra. Aun pudiendo aceptar en buena medida esta explicación, no siempre tiene por qué cumplirse. El problema reside en que, en la mayoría de las ocasiones, con los escasos datos proporcionados en los textos es muy difícil distinguir entre campamentos temporales y campamentos estables. Recintos castrenses establecidos en principio para un período muy corto podían durar varios meses. Las fuentes no informan de cual sería la práctica habitual en estas ocasiones, en el caso de que existiera alguna norma fija que seguir. Por otra parte, la arqueología retrasa la petrificación de los campamentos estables del limes renano hasta el último cuarto del siglo I d.C., después de casi un siglo de existencia. La documentación de campamentos de época republicana que emplean la piedra como material constructivo parece apuntar en la dirección de que no existía una norma única, sino adaptaciones diversas según las circunstancias militares concretas y la naturaleza del terreno, aunque no cabe duda que la estancia prolongada en un mismo recinto aconsejaría una edificación más sólida y duradera.

En principio podemos considerar que la inmensa mayoría de citas textuales sobre campamentos romanos se refieren a recintos construidos con madera. Este hecho complica sobremanera su posible localización y ex- 
cavación arqueológica, debido a la deficiente conservación de este material.

Por lo que se refiere a las fuentes clásicas referentes a los campamentos españoles, la situación resulta en todo semejante a la del resto del mundo romano. La práctica totalidad de las citas de los historiadores son localizaciones geográficas en un sentido amplio, sin datos concretos. Contamos con algunas referencias sumarias a técnicas de castramentación, que no aportan nada nuevo a lo ya conocido. Sin embargo, el largo y dificultoso proceso de conquista del territorio peninsular, prolongado a lo largo de dos siglos, requirió un gran despliegue bélico, que tiene su reflejo adecuado en el elevado número de campamentos dispersos por nuestra geografía. Las referencias a este tipo de recintos son más numerosas en Hispania que en la mayor parte de las regiones del Imperio.

\section{RECINTOS CASTRENSES ESPAÑOLES EN LA HISTORIOGRAFÍA GRECOLATINA}

El conocimiento exhaustivo de las referencias a recintos militares romanos dentro de las obras de los historiadores clásicos, tiene un valor excepcional para la arqueología española. Constituye el punto de partida en los intentos de localización geográfica de los campamentos establecidos por el ejército romano a lo largo del proceso de conquista, aunque por lo general aportan pocos datos concretos sobre la topografía de los lugares escogidos y su funcionamiento interno. Schulten inaugura los intentos de identificación arqueológica de recintos campamentales tomando como base los datos de los textos clásicos contemporáneos. Sin negar los indudables éxitos obtenidos mediante este sistema, los errores también han sido considerables. Toda la investigación arqueológica ha estado mediatizada hasta hace pocas décadas por la necesidad de ubicar históricamente cada asentamiento militar - encontrado de forma más o menos fortuita- dentro de los pasajes correspondientes de los historiadores romanos. La excavación propiamente dicha tenía una importancia secundaria, ya que estaba destinada a confirmar la atribución erudita del «arqueólogo". Se han identificado como campamentos romanos recintos que tenían poco que ver arqueológicamente, pero que se ajustaban bien al marco geográfico de sucesos históricos conocidos. Actualmente la identificación histórica constituye el fin, no el principio, del estudio, y a las fuentes se les atribuye una validez relativa.

En general encontramos referencias a establecimientos castrenses en todos los autores que tratan sobre el período de la conquista de la $\mathrm{Pe}$ nínsula. La monumental recopilación de SCHULTEN, las Fontes Hispaniae 
Antiquae (SChulten 1935, 1937, 1940), resulta de gran utilidad, aunque presenta el inconveniente de escoger en ciertas ocasiones entre citas similares de distintos autores, omitiendo algunas versiones consideradas menos claras o ilustrativas. Por otro lado recoge gran parte de las teorías de su compilador, que si bien posee conocimientos topográficos bastante amplios, no resultan suficientes para identificar campamentos sin mediar excavación científica alguna. En los últimos años se ha producido una revalorización de las tesis de Schulten, muchas de las cuales han sido comprobadas arqueológicamente.

Los autores que más noticias aportan sobre el tema son: Polibio (Historias, Libros III, X, XI, XXXV); Tito Livio (Ab Urbe Condita, Libros XXI, XXII, XXIII, XXIV, XXVI, XXVII, XXVIII, XXXIV, XXXIX, XL, XCI; Periochae 55, 92); Apiano (Iberia 16, 24, 25, 27, 43, 45, 46, 47, 48, 49, 50, 55, 58, 59, 64, 66-69, 76, 80, 83-92, 110-112, Bellum Civile I, 110-112); Frontino (Stragemata, Libros I, II), Plutarco (Vidas Paralelas... Tiberius Graccus y Sertorius); César (De Bello Civile I, De Bello Alexandrino 49, 59, 64, 57; De Bello Hispaniensi); Salustio (Historiarum Reliquiae II); Floro (Epitome Gestae Romanae, Libros I y II); Orosio (Adversus paganos 5); Dión Cassio (Historia romana, Libros LIII y LIV).

Como ya hemos mencionado anteriormente las citas suelen ser muy breves y concisas porque no es un tema que resulte especialmente atractivo para los historiadores antiguos. Pueden mencionar directamente el establecimiento de un recinto militar, pero por regla general suponemos su existencia por el contexto. Pocas veces se citan los campamentos de paso o las bases establecidas por el ejército romano para el asedio de núcleos de población y debemos formular hipótesis sobre el lugar aproximado donde se colocarían. Más frecuentes son las referencias a campamentos establecidos durante un período de tiempo bastante largo, como el caso específico de los hiberna. Pero incluso en estos casos las fuentes no pasan de localizarlos a determinada distancia de las poblaciones. Por poner un ejemplo, Livio en Historias XXXIV, 13, afirma que M. Porcio Catón estableció su campamento "a 3 millas de Ampurias", pero no aporta ningún dato más preciso.

Respecto a su distribución cronológica, se concentran lógicamente en los períodos más activos de las guerras de conquista. Existía un mayor número de soldados a los que dar cobijo, los movimientos tácticos militares eran más frecuentes y, sobre todo, la atención de los historiadores se centra durante estos momentos en Hispania. No podemos olvidar que es un proceso que requiere dos siglos de operaciones bélicas difíciles y casi continuas. Asímismo su distribución geográfica está íntimamente relacionada con las incidencias de la lucha contra los indígenas y con la 
penetración romana hacia el interior de la Península. En un primer momento los asentamientos castrenses aparecen ligados a las campañas contra los cartagineses y las bases romanas de retaguardia, y se distribuyen por la costa mediterránea y el Sur de la Península. Al principio a poca distancia de la costa, pero cada vez más alejados de ésta, conforme crece el interés imperialista romano y los procónsules se sienten más seguros en sus bases béticas y levantinas. Las campañas de Catón del 196-195 a.C. y las guerras contra celtíberos y lusitanos constituyen fases de gran actividad constructiva castrense en la Meseta, bastante bien documentada literariamente, pero concentrada en zonas muy concretas, que por lo general vienen determinadas por su posición estratégica respecto a las principales vías naturales de comunicación. Un nuevo período comienza con la participación de Hispania en las guerras civiles de los siglos II-1 a.C., concretamente como escenario de las contiendas entre Sertorio y los representantes senatoriales, y más tarde entre Pompeyo y César. Los criterios de localización de campamentos varían radicalmente en esta fase. Ya no se disponen contra un enemigo exterior, siguiendo una dirección Norte-Noroeste, las zonas más refractarias al control romano, sino contra un ejército parejo, que sigue idéntica estrategia militar. El establecimiento de recintos castrenses está en función del marco geográfico donde se desarrollen las operaciones militares, que pueden ser en cualquier lugar de la Península. Tenemos así campamentos en la Lusitania, el Valle del Ebro, la Bética, la Meseta, el territorio Vascón... Los primeros años del reinado de Augusto suponen la reanudación temporal del criterio de glacis defensivo, con la creación de establecimientos militares estables al pie de las montañas cantábricas.

Las citas a recintos campamentales en época imperial son escasísimas debido tanto a la pacificación general del Imperio y la transformación llevada a cabo en la concepción estratégica y la distribución de tropas, como al eclipse de las fuentes referidas específicamente a nuestro país. Las referencias al campamento de la legio VII Gemina en León y los datos de la Notitia Dignitatum para el siglo iv, constituyen las únicas excepciones, y muestran cierta continuidad de la política augustea y tiberiana que concentra la presencia militar al Norte de la Península por motivos aún no aclarados por completo, entre los que podemos apuntar la vigilancia minera, la conservación de la red viaria y el control de las costas septentrionales de la Península.

Las fuentes clásicas sitúan en la costa mediterránea los primeros campamentos romanos establecidos en nuestro suelo, concretamente en Tarraco. Resulta llamativo que a pesar de que el desembarco romano se produce en Ampurias (PoLIBIO III, 76, I), hasta la época de Catón no se menciona de modo específico la presencia de campamentos junto a dicha 
población, aunque no cabe duda que debieron existir. La cuestión del campamento o campamentos romanos en la colonia griega, incluso como origen probable de la ciudad romana, ha sido muy discutida por los arqueólogos, como veremos más adelante.

La ciudad de Tarraco constituye el primer asentamiento militar romano. Era una base naval de gran interés estratégico, empleada como campamento de invierno, como nos indican Polibio (Historias III, 76, 12; III, 95, 4 ; X, 40, 12) y Tito Livio (Ab Urbe Condita XXI, 61; XXII, 19 y XXII, 22). Constituía el punto de llegada de las flotas itálicas y un centro de aprovisionamiento seguro. Las excavaciones arqueológicas llevadas a cabo desde las primeras décadas de este siglo en la muralla romana han permitido confirmar el carácter militar del recinto fortificado, elevado en los últimos años del siglo III a.C. y reformado pocos años más tarde, a principios del II a.C. (HAuschild 1979).

En el desarrollo de las operaciones contra los cartagineses hay noticias directas de varios campamentos más. Polibio señala un campamento establecido por los Escipiones frente a la ciudad de Sagunto durante la campaña del año 217 a.C. (Historias III, 97, 6). Schulten identifica éste con los restos del recinto fortificado encontrado cerca de Almenara, $9 \mathrm{~km}$ al Norte de Sagunto (SCHULTEN 1928, 36); Livio señala la existencia de otro campamento romano en Castro Albo, al parecer Akra Leuke -Alicante-, abandonado por causa de las dificultades provocadas por el dominio púnico de la región, y sustituido por otro cerca del Monte de la Victoria (XXIV, 41), que Schulten localiza entre Alicante y el Ebro, posiblemente en el cabo de Cullera (SCHULTEN 1935, 84). Esto sucede a lo largo de las campañas de los años 214 y 212 a.C.; Apiano narra en el Capítulo XVI de su Iberia que Cneo y Publio Escipión invernaron separadamente durante el año 211 en Turdetania. El primero lo hizo en Orsón y el segundo en Cástulo. Es de suponer que lo harían en campamentos situados extramuros de los núcleos urbanos, por cuanto no podían fiarse de los indígenas y resultaba más acorde con sus costumbres.

Especial mención merece el campamento dispuesto por Escipión como base desde la que acometer la conquista de Cartagena. Polibio dice que acampó la Norte de la plaza, en el istmo que la separaba de tierra: "hizo tirar dos fosos por detrás del campamento y dos trincheras de mar a mar, y por delante, mirando a la ciudad, lo dejó sin defensa, porque la misma naturaleza del terreno le ponía bastante a cubierto de todo ataque" (PoLIBIO, Hist. $X, 9,7)$. Y un poco más abajo: «A la vista de una disposición de terreno semejante, aun sin defensa alguna, estaba bien asegurado el campo romano de parte de la ciudad sólo con tener a un lado el estero y al otro el mar. El espacio intermedio que unía la ciudad con el continente 
y venía a parar al centro de su campo, lo dejó sin trinchera alguna, bien fuese porque conviniese a su propósito no tener estorbo para las salidas y retiradas al campamento" $(X, 11,1)$. Livio da el nombre del lugar donde se asentó el campamento de Escipión: la colina de Mercurio (XXVI, 44, 6), identificado en la topografía actual como el Castillo de los Moros (SCHULTEN 1935, 101). Resulta una descripción muy ilustrativa, pero aún no han sido hallados restos de este campamento de madera, sin duda porque la rapidez de la toma de Cartagena en el 210 no requirió convertirlo en una base más sólida. Desconocemos, sin embargo, el lugar ocupado por la guarnición militar que, según Apiano, (Iberia 24) fue establecida a partir del año 208 en la antigua ciudad púnica, que bien pudo permanecer en este campamento temporal. Ramallo se inclina más por la ocupación de los cuarteles cartagineses situados en el interior de la población (RA. MALLO $1989,44-45)$. La zona parece haber sido muy modificada posteriormente.

Durante la agitada campaña del 206 a.C. tenemos constancia escrita de la existencia de varios campamentos de uno y otro bando. En la batalla de llipa - Alcalá del Río - los ejércitos chocaron a partir de campamentos situados en las inmediaciones (PoLIBIO XI, 21, 1, LIVIO XXVIII, 13); Una situación similar se produce ante Carmona (APIANO 27) y en un lugar identificado a orillas del Ebro (PoLIBIO XI, 32, 1 y LIVIO XXVIII, 33).

Estas citas nos ponen en contacto con una cuestión que no afecta directamente a nuestro estudio, pero no deja de plantear un interesante problema. Junto a los campamentos romanos encontramos numerosas menciones a la existencia de recintos militares púnicos, que son citados con el mismo término griego o latino que hace referencia a los primeros. Livio habla de campamentos púnicos en la zona del Ebro (XXIII, 29), en el mismo Monte de la Victoria, frente al campamento romano (XXIV, 41), en un montículo cercano a Baecula, tal vez la actual Bailén (XXVII, 18), así como los ya citados de llipa (XXVIII, 13-14) y del Ebro (XVIIII, 33); Apiano habla de un campamento en la Turdetania en el invierno de 211 (Iberia 16), y otros en Bailén (24) y Carmona (25 y 27); Polibio del de Ilipa (XI, 21, 1) y de un campamento de Asdrubal en los contornos de Cástulo; Existen otras citas similares a Frontino (Stragemata II, 10, 2) y algún otro autor. El interrogante que se nos plantea es si estos campamentos eran similares a los romanos o seguían un esquema y una concepción distinta. En el estado actual de nuestros conocimientos es imposible pronunciarse al respecto, pero algunas referencias dispersas nos hacen pensar que no habría muchas diferencias en su concepción y aspectos defensivos, si bien se separarían notablemente en su distribución interna debido a la composición radicalmente distinta de ambos ejércitos y a la presencia de elefantes en el africano. La cita de Polibio $X, 38,7$, 
donde narra la escogida posición de Asdrúbal del año 208 cerca de Cástulo, con sus espaldas resguardadas por un río y un amplio llano delante donde formar en orden de batalla, indica un desarrollado conocimiento de la táctica militar, al menos a un nivel semejante al practicado por el ejército romano. En otras citas se confirma esta cuidada elección. La presencia de una empalizada de madera y puertas apropiadas están testimoniadas en Livio (Ab Urbe Condita XXVII, 18 y XXVIII, 2). La helenización, tan intensa en este momento tanto en el mundo púnico como el romano, es posible que hubiera proporcionado un orden bastante estricto a ambos contendientes, manifestado en sus recintos castrenses. Sin embargo, la inexistencia de campamentos púnicos testimoniados por la arqueología, hace que aún nos movamos en el terreno de las hipótesis.

La época de Catón constituye un momento trascendental dentro del largo proceso de conquista de la Península Ibérica. La intensa actividad desplegada por el cónsul cristaliza en la construcción de un elevado número de edificaciones castrenses. A través de tres citas sabemos de la existencia de un recinto militar de Ampurias. Livio, en XXXIV, 11 nos ofrece esta escueta noticia. Un poco más abajo (Ab Urbe Condita XXXIV, 13) lo califica como un campamento de invierno, localizándolo a tres millas de Ampurias. Frontino corrobora la noticia (St ragemata I, 2, 5). Desconocemos si las citas de Tito Livio corresponden a un único campamento o a dos, pero su existencia resulta incontestable. Historiadores y arqueólogos han intentado en vano localizarle en el solar de la misma ciudad romana (PUIG I CAdAFALCH 1934, 65) o en sus cercanías (SCHULTEN 1935, 183; ALMAGRo BASCH 1951, 72-73; RIPOLL 1978, 45; RIPOLL y LLONGUERAS 1974). Recientes excavaciones han revelado diversas estructuras que podrían asociarse, a través de la cronología de los materiales, con el praesidium catoniense, elevado a comienzos del siglo II a.C. (AQUILUE y VV.AA. 1984, 36-47).

Mucha bibliografía ha originado asimismo la expedición del cónsul por la Celtiberia a su regreso del Mediodía peninsular. Aunque no se cita directamente ningún recinto, éstos debieron existir. Algunos autores han interpretado los episodios del cerco de Segontia - Sigüenza- y del camino de regreso al Ebro a través de la Submeseta Norte como el origen de los campamentos de Aguilar de Anguita (SCHULTEN 1928, 36) y del primer recinto de Renieblas (SCHULTEN 1929, 3 7-38) respectivamente, aunque carecemos de pruebas fehacientes que respalden esta atribución. De ser cierta ésta nos encontraríamos con los primeros campamentos establecidos en el ámbito de la Meseta.

Del período que se extiende entre el 195 a.C. y el comienzo de las campañas contra Numancia y los pueblos lusitanos tenemos citas dis- 
persas. Las fuentes apenas hablan de Hispania en este momento, y sólo las esporádicas sublevaciones contra el poder romano merecen algunas líneas. En el marco de éstas se inscriben varios puestos fortificados romanos. En las operaciones del año 186-185 a.C. por tierras de la Carpetania se establecen dos campamentos "No lejos de Dipo y Toletum" (LIVIo XXXIX, 30). El mismo pasaje da por primera vez la noticia de la existencia de cuarteles de invierno en la Turdetania. Ignoramos si serían fijos o temporales, y si estarían intramuros de alguna ciudad o fuera de su perímetro. Referencias posteriores citan Córduba como asiento de los mismos. Durante la campaña del 181, también en Carpetania, el procónsul Q. Fulvio Flaco sitúa su campamento cerca de Ebura (?), instalando en ella un pequeño destacamento (LIVIO XL, 30). Las actividades llevadas a cabo en la Celtiberia por T. Sempronio Graco en los años 180-179 llevan a la erección de campamentos temporales en la zona, uno cercano a Alca (LIvio XL, 49), y otro a Complega (APIANo, Iberia 43). También aquí hay mención a los campamentos de invierno (LIVIO XL, 35 y 39).

Las guerras y asedios contra Numancia, que se desarrollan entre el 154 y el 133, concentran sin duda la mayor cantidad de referencias a recintos militares en todo el proceso de la conquista peninsular. La larga duración de la campaña y el desgaste físico y psicológico que produjo en la propia metrópoli, atrajeron la atención de los historiadores hacia este episodio. Contamos además con la experiencia cercana de Polibio, que participó en el sitio desde el campamento de Escipión y contempló el sometimiento de la ciudad, si bien los pasajes de su obra dedicados a esta cuestión se han perdido. Por otro lado, un tema con estas connotaciones nacionalistas ha sido magnificado por la investigación española, que le ha dedicado numerosos estudios basándose casi exclusivamente en los datos de las fuentes. Los sucesos de la guerra Celtibérica no se circunscriben al ámbito de la ciudad arevaca. Apiano, en Iberia 45, narra las campañas del cónsul Q. Fulvio Nobilior contra Segeda. Algún autor ha atribuido la fundación del campamento de Almazán al mencionado procónsul, con ocasión de su marcha desde Ocilis -Medinacelihasta Numancia en el año 153 a.C. (SCHULTEN 1937, 12). No hay una cita específica y los argumentos parecen ser más lógicos y topográficos que científicos. Un año más tarde, en el 152, las fuentes (APIANO 48-49) sitúan un nuevo ejército romano al mando de Claudio Marcelo acampado en las cercanías de Ocilis. Quizá correspondan a esta campaña los recintos de Almazán, (GAMER-OrTego, 1970) y Aguilar de Anguita (Morillo, 1991, 14950). En cualquier caso, la presencia de estos campamentos atestigua la importancia atribuida por los romanos a la vía que remonta el Jalón desde el Ebro para penetrar tanto en la Submeseta Sur como en la Norte a través del puerto de Esteras. 
Las menciones o campamentos cercanos a Numancia son muy abundantes, como dijimos arriba. Apiano, 46 relata el episodio que conduce al asentamiento del primer recinto militar junto a Numancia en el 153 a.C.: "Los arevacos se congregan esta misma noche en Numancia, ciudad muy poderosa, y eligen como jefes a Ambón ya Leucón. Nobilior les siguió a tres días de distancia y acampó a veinticuatro estadios de ellos". Un poco más abajo (47) continúa: “Nobilior, desconfiando de todo, pasó el invierno en su campamento, techándolo como pudo, y teniendo dentro las provisiones; pero sufrió mucho por la escasez de éstas y por las fuentes nevadas y la crudeza del frío...». Schulten identificó este campamento con el recinto número tres de la Gran Atalaya de Renieblas (SCHULTEN 1914, 305). Al año siguiente, el 152 a.C., el sucesor de Nobilior, Claudio Marcelo, vuelve a acampar a cinco estadios de Numancia (APIANo 50). En esta ocasión, Schulten lo sitúa en el Cerro Castillejo, cuya distancia a la ciudad, $1 \mathrm{~km}$, se corresponde con la proporcionada por las fuentes (SCHULTEN 1927, 175). En este mismo lugar localiza el de Q. Pompeyo Aulo, del 141 a.C. (SCHULTEN 1927, 181), aunque las fuentes sólo mencionen que el procónsul «acampó ante Numancia» (APIANo, Iberia 76).

Parece que al menos durante una década existió un asentamiento militar romano establecido de forma más o menos continuada frente a $\mathrm{Nu}$ mancia. En el 140 a.C. Pompeyo pasa parte del invierno en el campamento anteriormente citado (APIANO. 48), pero no pudiendo resistir las duras condiciones del clima y el acoso de los numantinos, se retiró a mitad de la estación hacia sus cuarteles de invierno de la costa levantina (SCHULTEN 1937, 42); De nuevo en el cerro del Castillejo emplaza Schulten el campamento de C. Hostilio Mancino en el año 137 (SCHULTEN 1937, 47), pasaje que aparece citado con AP. 80, Livio, Periochae 55 y Plutarco, Vidas... Tib. Graccus 5.

El procónsul del 135 a.C., C. Calpurnio Pison, no se atreve a invernar junto a Numancia y lo hace en algún lugar de la Carpetania (APIANO, Iberia 83). A su llegada en el 134 a.C. y en opinión de Schulten (SCHULTEN 1937, 63), P. Cornelio Escipión el Africano debió encontrar el ejército en Tarraco (APIANO, Iberia 85). En algún lugar del Valle del Ebro tuvo lugar el entrenamiento y reorganización de las desmoralizadas tropas romanas (APIANO 86). Estas actividades son recogidas por varios autores entre los que destacan Floro, Orosio y Apiano. Este último constituye la fuente más completa. El relato de Polibio, espectador de excepción de la campaña numantina, se ha perdido. Antes de acampar frente a la ciudad arevaca, Escipión dio un amplio rodeo, dirigiéndose al territorio de los vacceos para cortar los posibles apoyos militares y suministros de grano a Numancia. A su paso establece varios campamentos, uno de los cuales se situó junto al núcleo indígena de Coplanio, situado en las proximidades 
de Pallantia (APIANo, Iberia 88). Ese año invernó en la región de Numancia, no sabemos exactamente en que lugar (APIANO 89).

Quizá el pasaje más conocido de las guerras de conquista de la Península sea el que describe el establecimiento del cerco de Escipión en torno a Numancia. "No mucho después, habiendo instalado sus dos campamentos cerca de Numancia, puso uno a las órdenes de su hermano Máximo, el otro bajo su propio mando"... "Levantó siete castillos alrededor de la ciudad y empezó el asedio... "dio orden de rodear la ciudad con un foso y una valla" (APIANO 90-92). Floro en I, 34, 11, presenta una versión ligeramente diferente, al decir que eran cuatro campamentos. Schulten realizó una imaginativa interpretación de los restos conservados pertenecientes a las obras de circunvalación de Escipión (SCHULTEN 1927). El investigador alemán halló los restos de siete campamentos construidos en piedra y unidos por un muro de $4 \mathrm{~m}$ de anchura, lo cual parece ajustarse bastante bien a los datos de los textos, aunque alguna de sus identificaciones son un tanto discutibles.

Durante las campañas contra los lusitanos los recintos fortificados más comúnmente citados son los cuarteles de invierno de Córdoba, como narran Polibio en XXXV, 2 y Apiano, 66. En otros pasajes solamente se mencionan los hiberna en Turdetania (APIANO 58-59 y 64 y FLORO I, 33, 15). Al parecer la cercanía de la capital meridional al frente lusitano y el carácter de guerra de guerrillas de los lusitanos desaconsejaban un campamento base situado en profundidad.

Durante los años 141-140 a.C. el procónsul Fabio Máximo Serviliano construye un gran campamento en algún lugar de los márgenes de la Lusitania, la famosa Castra Servilia mencionada en Apiano (Iberia 67-69), identificado por algunos investigadores con el campamento de Cáceres el Viejo (BELTRÁn LLORIS 1973-1974, 296-298). El asentamiento de Casta Liciniana, citado como vici por Tolomeo (Geographia II, 5, 8) y Plinio (Naturalis Historia IV, XXII, 117) se ha puesto en relación con las campañas desarrolladas por P. Licinio Craso contra los lusitanos en los años 96-94 a.C.

La sublevación de Sertorio en la Península supone otro período de gran actividad constructiva en el ámbito militar. Los ejércitos contendientes se mueven en amplias zonas de Hispania, sobre todo en la Lusitania, la meseta superior, la costa levantiva y el Valle del Ebro, regiones sometidas al control del rebelde. La primera fase de la guerra sertoriana se desarrolla en tierras lusitanas. Entre los años 83 y 78 a.C. tienen lugar distintos movimientos de penetración y retroceso por parte de ambos ejércitos. La expedición fracasada de $Q$. Caecilio Metelo del 79-78 ha sido para muchos investigadores la causa de la fundación de varios puestos militares forti- 
ficados - Metellinum, Vicus Caecilius, Castra Caecilia-, aunque las fuentes no mencionan ningún asentamiento de forma específica. Las excavaciones arqueológicas llevadas a cabo recientemente por Ulbert en el recinto militar de Cáceres el Viejo han permitido establecer una cronología asimilable a la guerra sertoriana, lo que le lleva al investigador a identificarlo como la Castra Caecilia de las fuentes imperiales, campamento de invierno fundado por Q. Caecilio Metelo (Ulbert 1984, 207-208).

Durante el mismo año tienen lugar operaciones en la Hispania Citerior, donde se mencionan campamentos de Pompeyo y de Hirtuleyo (Orosio, Adversus Paganus V, 23, 3 y 5). Livio menciona específicamente en su Libro $\mathrm{XCl}$ unos cuarteles de invierno sertorianos junto a la ciudad de Castra Elia, en la región del Ebro. El nombre resulta muy significativo pero desconocemos quién le da ese nombre y en qué momento. Schulten la sitúa en la confluencia del Jalón con el Ebro (SCHULTEN 1937, 181). Plutarco (Sertorio 16) hace referencia a un campamento en las cercanías del Ebro, posiblemente el mismo que se cita en Livio XCl. Otro recinto militar es el instalado el año 76 junto a Calagurris, en la otra orilla del río Ebro (LIVIO XCl).

Pompeyo permanece el invierno del 76-75 en la Celtiberia, en un recinto desconocido (Salustio, Historiarum Reliquiae II, 98, 5-6. El mismo autor, en II, 94 dice: “(Pompeyo) Ordenó al legado Titurio que pasase el invierno en la Celtiberia con quince cohortes, a la cabeza de los aliados". Algunos autores han creído identificar los campamentos invernales del legado pompeyano en el campamento $V$ de Renieblas (SCHULTEN 1937, 221). A finales del 75 a.C. Pompeyo se retiró al territorio de los vascones, donde estableció un campamento (Salustio, Hist. Rel. II, 93). En el Capítulo XXI de su obra Sertorius, Plutarco, refiriéndose a los mismos acontecimientos, afirma que Pompeyo pasó el invierno entre los vacceos, confusión ésta que parece deberse a un error del autor o del copista medieval. En estos pasajes se han basado los investigadores que intentan demostrar el origen castrense de la ciudad de Pamplona, presumiblemente reflejado en la filiación pompeyana del nombre latino de esta localidad, Pompaelo (MezQuiriz 1958, 9).

Otros centros temporales de este momento son localizados en Sucro (Plutarco, Sertorius 19 y ApIano, Bellu $m$ civile I, 110), a orillas del Turia (SCHULTEN 1937, 210), en Sagunto (APIANo, Bellum Civile I, 110) y de nuevo en Calahorra (APIANO, Bellum Civile I, 112).

Las operaciones militares que tuvieron lugar en la fase hispana de la guerra entre Pompeyo y César son descritas de forma minuciosa en las propias obras del Dictador. Esta meticulosidad afecta asimismo a los recintos castrenses, para cuya localización César ofrece numerosas refe- 
rencias topográficas. Sin embargo carecemos de testimonios arqueológicos acerca de los mismos. Eran campamentos temporales, de madera, sin grandes obras de fortificación, preparados como soporte a batallas decisivas. Los campos de batalla principales han sido estudiados con las obras de César en la mano por historiadores y topógrafos, y resulta bastante convincente la reconstrucción de sus movimientos sobre el terreno (Stoffel 1887; Schneider 1887; Veith 1906; Holmes 1923). Los campamentos se concentran en torno a llerda (CÉSAR, De Bello Civile I, 38; I, $41 ;$ I, 48; I, 61; I, 63, 72), llipa (CÉSAR, De Bello Alexandrino 57), Córdoba (CÉSAR, De Bello Alex. 59, De Bello Hispaniense 5 y 34), y entre Ucubi y Ategua -Teba la Vieja- (CÉSAR, De Bello Hispág. 6-10, 20, 23, 27, 29). De nuevo son mencionados los cuarteles de invierno de Córduba (De Bello Alex. 49, 64).

Tenemos muy pocos testimonios acerca de la conquista de los pueblos del Norte peninsular, llevada a cabo por Augusto entre los años 26 y 19 a.C. Menos frecuentes aún son los datos referentes a los siglos posteriores. Las fuentes principales para este período son Estrabón, Floro, Dión Cassio y Orosio. Conocemos solamente el emplazamiento aproximado de uno de los campamentos de las Guerras Cántabras, cerca de Sasamón. Floro en II, 33, 48 Narra: "César en persona vino a Segisamam y estableció el campamento". Orosio $(\mathrm{VI}, 21,3)$ repite a Floro: “Así pues, César puso un campo junto a Segisama...". Sin embargo, hasta el momento no han aparecido en Sasamón restos de edificios o materiales arqueológicos que avalen una presencia militar augustea (ABASOLo 1975, 127-32). Tal vez debamos entender en un sentido amplio la expresión “junto a Segisama», y las citas se refieran a algún núcleo de menor entidad cercano a la ciudad turmoga, tal vez Herrera de Pisuerga, donde existen suficientes datos para asegurar la presencia, al menos en un momento algo posterior, de la Legio IV Macedonica (entre otros Pérez González 1989; Morillo Cerdán 1992).

Tanto Floro como Osorio relatan asimismo el episodio del ataque de los astures contra los tres campamentos romanos establecidos en la Asturia Augustana (FLoRo II, 33, 54 y Orosio VI, 21, 9), para Schulten en la región de Brigaecium -Benavente- (ScHuLTEN 1940, 196). El Capítulo XXXIII, LIV, del Libro II del Epitome Gestae Romanae de Floro contiene una cita considerada trascendental para conocer el origen de las ciudades campamentales en Hispania: "(Augusto)... quien recelando del amparo ofrecido por los montes en los que se refugiaban (los indígenas), les ordenó habitar y establecerse en los campamentos situados en la llanura. Allí había el consejo del pueblo, y aquel poblado recibía los honores de capital». Debido a la posición concreta que ocupa este pasaje dentro del relato de Floro, inmediatamente después de la campaña contra los astures y la toma de Lancia, la investigación ha considerado que esta cita hacia 
referencia a Asturica Augusta, la actual Astorga, capital del Convento Jurídico asturicense, lo que ha servido tradicionalmente de argumento para buscar un origen castrense para la capital maragata (SCHULTEN 1943, 154; MAÑANES 1976, 77-78; MAÑANES 1983, 146), recientemente puesto en cuestión (García Marcos y Vidal Encinas 1990, 35).

De la modificación y redistribución de fuerzas militares dentro de las provincias hispanas en época de Tiberio queda constancia en Estrabon (Iberia III, 3, 8 y III, 4, 20). Este autor nos comenta que Tiberio estableció entre los Cántabros y Astures tres legiones, dos al mando de un legado en la región al Norte del Duero, y la restante al mando de otro legado en el sector que se extiende entre el límite de los cántabros y astures y los Pirineos. En ningún momento se dice el nombre de las legiones, dónde fueron emplazadas y si las dos primeras acampaban juntas o separadas. Tampoco sabemos la fecha de la reordenación. Sólo la arqueología nos puede ilustrar a este respecto. Grandes campamentos parcialmente excavados como los de Herrera de Pisuerga, (Palencia) y Rosinos de Vidriales, en Zamora, pertenecen a este período (MARTín VALLS-DELIBES DE CASTRO 1975).

Gracias a los textos de los geógrafos y a los itinerarios de los siglos al III d.C., sabemos del estacionamiento en el solar de León de la Legio VIII Gemina, sin lugar a dudas en un campamento construido a tal efecto. Por el momento debemos considerar que la erección del campamento tuvo lugar hacia el 74 d.C., momento de regreso de la legión a Hispania (GARCía Y BeLLIDo 1968b), a pesar de la existencia de materiales arqueológicos de cronología julio-claudia, que plantean la existencia de un asentamiento anterior a un tipo aún no bien definido (MORILlo Cerdán 1991, 168).

La mención más tardía a establecimientos castrenses en España la tenemos en el documento bajoimperial conocido como la Notitia Dignitatum, exhaustivamente analizado por diversos autores (entre los últimos trabajos debemos mencionar los de GOODBURN y BARTHOLOMEW 1976 y ARCE 1980). En el pasaje XLII, 1, 25 aparecen una serie de unidades militares emplazadas en varios puntos del Norte y Noroeste: León, Lugo, Paetaonium - Rosinos de Vidriales-, Veleia - quizás Iruña - y luliobriga, asiento de la Cohors I Celtiberorum, trasladada a este lugar desde Brigantium. No todos estos recintos han podido ser testimoniados por la arqueología (MORILLO CERDÁN 1991, 170-176). Por otra parte, los cambios conceptuales sufridos por la organización del ejército romano bajoimperial nos hacen poner en duda que tales unidades ocupen asentamientos exclusivamente castrenses. Más bien podemos pensar en la existencia de guarniciones militares en poblaciones civiles. En estos momentos resulta 
muy difícil deslindar entre las funciones militares y civiles de algunas ciudades, buen ejemplo de lo cual es el desconocimiento acerca de los motivos que impulsan la edificación de potentes murallas en núcleos urbanos de una u otra manera vinculados al ejército.

Por último debemos aludir, aunque sea brevemente, a los escasísimos datos proporcionados por las fuentes sobre las tácticas de asentamiento castrense. De la lectura de Livio (Ab Urbe Condita XL, 33) podemos deducir que los indígenas veían el campamento como un sistema organizativo típicamente romano, de tal modo que la ausencia de recinto campamental romano les lleva a caer en una trampa ante Contrebia en el 181 a.C. La fuente no debe referirse a cualquier tipo de recinto militar, sino al específico de la milicia romana, e implica que los indígenas no conocian nada similar. Cuestión de interés es la continua mención a campamentos de invierno en regiones como Turdetania y Cataluña, bien controladas por Roma. Desconocemos cual sería la disposición de estos hiberna. No sabemos si existirian recintos propiamente dichos dentro o fuera del perímetro de la ciudad, así como su articulación con el resto del núcleo civil. En principio cualquiera de las dos posibilidades resulta válida. La cita de Plutarco en su obra Sertorius 6, arroja un poco de luz. Narrando la molicie y dejadez de la soldadesca a la llegada del general, dice que éste obligó a las tropas a construirse barracas fuera de las ciudades. Es posible que ésta fuera la práctica ortodoxa, aunque no siempre se llevara a cabo.

Existen algunos datos sobre la flexibilidad de los generales romanos a la hora de establecer su campamento. El pasaje de César en De Bello Alex. 59 resulta de los más curiosos: se establecen los campamentos enemigos sobre alturas del terreno, a la vista del otro, cerca del agua. Incluso uno de los campamentos se adosa a la muralla de la ciudad de Ulia para que "las fortificaciones de la ciudad lo defendiesen de todos lados".

El Capítulo LXIV de la obra anteriormente citada ilustra la costumbre polibiana de adosar dos campamentos en uno solo (Historias VI, 32, 6-8).

\section{ALGUNAS OBSERVACIONES FINALES}

Las fuentes escritas proporcionan cierto número de datos sobre la localización y disposición interna de los campamentos romanos en España. Sin embargo, en su mayor parte no son referencias detalladas, sino puntuales y poco precisas, mencionadas al socaire de los principales 
acontecimientos narrados a lo largo de las campañas militares realizadas contra los pueblos indígenas o con ocasión de los enfrentamientos entre distintas facciones políticas romanas. Los historiadores clásicos suelen pasar a vuelapluma sobre esta cuestión, considerándola sin duda de poco interés para el lector contemporáneo. Tan sólo en algunos casos concretos, como por ejemplo el cerco de Numancia, se hace hincapié en aspectos concretos del emplazamiento y la edilicia castrense. A causa de este peculiar tratamiento de los recintos militares dentro de los textos del período de la conquista, resulta casi imposible identificarlos con una mínima garantía de seguridad, siempre y cuando no se lleve a cabo una exploración directa del terreno complementada con una excavación arqueológica de los recintos encontrados. No podemos dejar de señalar la enorme labor desarrollada por Schulten, cuya clarividencia y conocimiento del terreno le llevó a localizar y datar, con las fuentes en la mano, buena parte de los campamentos romanos catalogados hoy en día en nuestro país. Recientes excavaciones están demostrando hasta que punto el investigador alemán acertó en sus, a veces demasiado apresuradas, atribuciones.

Los textos clásicos muestran asimismo un reparto muy irregular de los recintos castrenses por toda la geografía peninsular. Los campamentos se concentran especialmente en dos áreas marginales de la Hispania republicana: la Submeseta Norte, y Extremadura, aunque en los momentos iniciales de la presencia romana se detecta una fuerte actividad constructiva en la costa catalano-levantina. No cabe duda que las razones de esta concentración hay que buscarlas en la actividad militar, primero contra los púnicos, más tarde contra celtíberos y lusitanos y por último con motivo de las guerras civiles. La presencia de hiberna o campamentos de invierno en Tarraco y Córduba queda atestiguada en varios pasajes de los textos. El papel desempeñado por estas dos poblaciones como capitales de las dos provincias hispanas - Citerior y Ulterior respectivamente-, centros de decisión y aprovisionamiento, explica este hecho perfectamente, aunque desconozcamos si el asentamiento militar se realizaba intramuros o extramuros de ambas ciudades. No obstante existen campamentos de invierno temporales -Cástulo, Ampurias, alrededores de Numancia...- cuando las razones tácticas de una campaña militar así lo aconsejaban.

Relatos como el del asedio de Numancia nos ilustran perfectamente sobre la desarrollada poliorcética romana del siglo II a.C. Pieza básica dentro del cerco de murallas eran los campamentos fortificados que servían de apoyo y punto de unión entre los diferentes lienzos de muro. La posición de los asentamientos militares numantinos ha podido ser establecida sobre el terreno mediante los precisos datos de Apiano, lo que 
constituye una de las aportaciones más valiosas de las fuentes escritas al terreno de la arqueología. Ejemplos como el de la localización de los campamentos numantinos son difíciles de repetir en cualquier otro caso, debido a la pobreza de los datos con los que contamos para otros recintos.

Las fuentes hispanas no aportan ninguna información sobre las técnicas de castramentación romana. Debemos suponer que los campamentos establecidos por las tropas romanas en nuestro país seguirian los principios generales establecidos por Polibio y más tarde repetidos por Higinio. La mayor parte sería de madera, por lo que su localización se revela como casi imposible, pero no existe modo de distinguir cuándo los textos hacen referencia a campamentos en materiales más sólidos. La arqueología ha revelado que la posición, los materiales constructivos y la estructura interna de los recintos no siguen unas normas tan estrictas como los textos de los tratadistas en castramentación pudieran llevarnos a pensar (MORILLO CERDÁN 1991). La adaptación a las condiciones topográficas y geológicas del terreno, así como a los imperativos de la táctica militar y -ipor qué no?- al criterio particular de cada general, debían introducir un cierto componente de improvisación en las costumbres habituales. Tan sólo la excavación científica de cada recinto encontrado puede aportar alguna luz al respecto. El conocimiento arqueológico de los campamentos hispanos, aún bastante limitado, constituye una fuente de información de extraordinaria importancia para conocer la evolución general del campamento romano, especialmente durante el período republicano.

\section{FUENTES}

APIANo, Iberia.

-, Bellum Civile.

CÉsAr, De Bello Gallico.

-, De Bello Alexandrino.

-, De Bello Civile.

-, De Bello Hispaniense.

Dión Cassıo, Historia Romana.

FLAVIO JOSEFo, Bellum Iudaicum.

Floro, Epitome Gestae Romanae.

Frontino, Stragemata.

HIGINIO (Pseudohiginio), De Metatione (o De Munitionibus) Castrorum. 
Julio Africano, Cestes.

LEÓN EL FILósofo, Institutiones Militares.

LIVIO, Ab Urbe Condita.

-, Periochae.

Onosio, Addversus paganos.

PLINIO, Naturalis Historia.

Plutarco, Sertorius.

-, Tiberius Graccus.

PoLIBIO, Historias.

Salustio, Historiarum Reliquiae.

Tito Livio, Ab Urbe Condita.

-, Periochae.

TOLOMEO, Geographia.

VEGECIO, Epitome Rei Militari.

Vitrusio, De Architectura.

\section{BIBLIOGRAFIA}

Abasolo, J. M. (1975): “Notas sobre el campamento romano de Sasamón (Burgos)", Pyrenae 11 , págs. 127-132.

ALMAGRo BASCH, M. (1951): "Las fuentes escritas referentes a Ampurias", Monografias ampuritanas I, págs. 72-73.

AquiLUE, J.; VV.AA. (1984): El Forúm romà de Empuries. Barcelona.

ARCE, J. (1980): "La "Notitia Dignitatum" et l'armée romaine dans la diocesis Hispaniarum", Chiron 10, págs. 593-608.

Beltrán Lloris, M. (1973-1974): “Problemas de la arqueología cacereña: el campamento romano de Cáceres el Viejo (Cáceres). Estudio numismático", Numisma 23-24, págs. 255-310.

GAMER, G.-ORTEGo, T. (1970): “Nuevas observaciones sobre el campamento romano de Almazán, (Soria)" Celtibena 39, págs. 67-79).

García y BelLIDo, A. (1968): "León y la Legio VIII Gemina con motivo del XIX Centenario de su creación", XIX Centenario de la Creación de la Legio VII Gemina. Programa General. León, s/ p. Nuevos estudios sobre la Legio VII Gemina y su campamento en León, León, 1968b.

García Marcos, V.; Vidal Encinas, J. M. (1990): Arqueología en Asturica Augusta (Astorga. León). León.

Goodburn, R.; Bartholomew, P. (1976): Aspects of the Notitia Dignitatum, British Archaeological Reports (Int. Series) 15.

HAUSCHILD, T. (1979): "Die römische Stadtmauer von Tarragona. Ausgrabungen in der Torre Minerva und in Baluarte de Santa Bárbara. Kampagnen 1976 bis 1978", Madrider Mitteilungen 20, págs. 204-237 (ed. catalana en Arquitectura romana de Tarragona. Tarragona 1983, págs. 131-180).

HOLMES, R. (1923): The Roman Republic and the founder of the empire III. London.

LENOIR, M. (1986): "Le camp romain et l'urbanisme hellénistique et romain", La fortification dans I'Histoire du Monde grec. Colloque Int. CNRS. Valbonne 1982, pub. París,págs. 329-336, figs. 325-331.

Mañanes, T. (1976): “Asturica Augusta", Sympos ium Ciudades Augusteas II. Zaragoza, págs. 77-84. 
- (1983): “La implantación romana en el territorio leonés”, Lancia, 1 págs. 139-183.

martín Valls, R., y Delibes de Castro, G. (1975): Sobre los compamentos de Petavonium, Studia Arqueologica, 36.

MASQUELEZ, E.,(1887): "Castra" en Daremberg-Saglio. Dictionnaire des antiquités grecques et romaines I. Paris, págs. 940-959.

Mezouiriz, M. ${ }^{a}$ A. (1958): Pompaelo I. Campaña de 1956. Pamplona.

Morillo Cerdán, A. (1991): "Fortificaciones campamentales de época romana en España", Archivo Español Arqueologia 64, págs. 135-190.

- (1992): Cerámica romana de Herrera de Pisuerga (Palencia, España): las lucernas. Santiago de Chile.

Pérez González, C. (1989): Cerámica romana de Herrera de Pisuerga (Palencia, España): la tierra sigillata. Santiago de Chile.

Puig I CAdAFAlCH, J. (1934): La arquitectura romana a Cataluya. Barcelona.

Ramallo, S. (1989): La ciudad romana de Carthago Nova. La documentación arqueológica. Murcia.

RIPOLL, E.; LLONGUERAS, M. (1974): “Embarcadero romano de Riells, en el ámbito empuritano", Miscelanea Arqueológica I. XXV Aniversari dels cursos Int. de Preh. i Arg. a Empuries (19471971). Barcelona, págs. 277-297.

RIPOLL, E. (1978): Els origens de la ciutát romana d'Empuries, Discurso leído el día 8 de juny de 1978 en la Reial Acadèmia de Bones Lletres de Barcelona. Barcelona.

SCHNEIDER, A. (1887): Merda. Berlín.

SCHulten, A. (1927): Numantia. Die Ergebnisse der Ausgrabungen 1905-1912. N. Die Lager bei Renieblas. Múnich.

- (1928): “Campamentos romanos en España», Investigación y Progreso 5 (mayo), págs. 3436 [ed. alemana en Forschungen und Fortschritten 5, págs. 1-3].

- (1929): Numantia. Die Ergebnisse der Ausgrabungen 1905-1912. II. Die Stadt Numantia. Múnich.

- (1935): Fontes Hispaniae Antiquae III. Barcelona.

- (1937): Fontes Hispaniae Antiquae IV. Barcelona.

- (1940): Fontes Hispaniae Antiquae V. Barcelona.

- (1943): Los Cántabros y los Astures y su guerra con Roma. Madrid.

StOFfEL, J. (1887): Histoire de Jules Cesar. Guerre civile I. París.

ULBERT, G. (1984): Cáceres de Viejo. Ein Späterepublickanisches Legionslager in Spanish-Extremadura. Madrid Beitrage XI, Mainz.

VEITH (1906): Geschichte der Feldzüge C. Julius Caesars. Berlín. 